\title{
Delírios da língua: considerações acerca da obra Tutaméia, de Guimarães Rosa - um encontro com Gilles Deleuze
}

\author{
Alex Fabiano Correia Fardim* \\ Samantha Pires dos Santos ${ }^{\star \star}$
}

\section{Resumo}

Pretendemos abordar Tutaméia, de Guimarães Rosa, enquanto obra de arte. Para isso, perguntamos: o que torna um livro uma obra de arte? Nesse itinerário, abordaremos o pensamento de Gilles Deleuze como principal referência. Se a literatura interessa-se pela filosofia, se o próprio Guimarães Rosa, no prefácio "Aletria e hermenêutica", extrapola o limite da produção artística em direção a uma propositura conceitual do fazer literário, também a filosofia interessa-se pela literatura, quer porque dela espere um engajamento em certo sistema de pensamento, quer por que encontre o refúgio de todos os sistemas. Deleuze coloca a arte ao lado da filosofia e da ciência como os três modos fundamentais do pensamento. A cada uma dessas caberia uma relação própria, um devir próprio, um modo diverso de relacionar acontecimentos e estados-de-coisas, correspondendo à arte o papel de "incorporar" acontecimentos, tornar acontecimentos "blocos de sensação". Nesse sentido, as considerações, portanto, que deixam entrever uma compreensão do último livro de Rosa, o qual, por algumas vezes, recorre a elementos intertextuais, não deixam de ser uma compreensão eminentemente intratextual, uma perspectiva do livro pelo livro que se recusa a buscar na figura do autor-pessoa, ou em categorias tomadas de empréstimo à psicologia, à psicanálise, à sociologia ou a qualquer outra ciência, os elementos necessários à sua sustentação. Buscaremos, com isso, uma compreensão, e, ao mesmo tempo, deixar abertas as múltiplas perspectivas sobre a obra, uma vez que é próprio dessa compreensão perspectivista manter o livro aberto, como infinitude da narrativa.

Palavras-chave: Literatura. Obra de arte. Filosofia. Bloco de sensação.

\footnotetext{
Doutor em Filosofia. Professor do Mestrado em Letras/ Estudos Literários (Literatura Brasileira) e do Departamento de Filosofia da Universidade Estadual de Montes Claros, MG. E-mail: alex.jardim38@hotmail.com.

** Mestre em Literatura Brasileira pela Universidade Estadual de Montes Claros, Unimontes, MG. E-mail: pires.samantha@gmail.com.
}

Data de submissão: abr. 2013 - Data de aceite: ago. 2013 http://dx.doi.org/10.5335/rdes.v9i2.3850 


\section{Introdução}

Maurice Blanchot, com a perspicácia que lhe conferia o duplo ofício de literato e filósofo da literatura, afirmou que "a obra é a espera da obra" e em decorrência disso que "somente nessa espera se concentra a atenção impessoal que tem por vias e por lugar o espaço próprio da linguagem" (2005, p. 352). A essa afirmação acrescentamos: a obra será, no limite, a ausência da obra, seu silêncio. Não se joga com as palavras quando se afirma que o vazio constitui o cerne da narrativa moderna, assim como o silêncio que se deve impor ao ruído incessante constitui o lugar próprio da literatura. Que haverá de espantoso, então, na tentativa de um autor de levar sua escrita até o limite do escritível, ali onde as palavras já não se concatenam na monotonia da denotação e da narrativa? A nosso ver é justamente esse o projeto radical de Tutaméia.

Se a literatura interessa-se pela filosofia, se o próprio Guimarães Rosa no prefácio Aletria e hermenêutica extrapola o limite da produção artística em direção a uma propositura conceitual do fazer literário, também a filosofia interessa-se pela literatura, pelo engajamento dessa em certo sistema de pensamento, ou por nessa encontrar o refúgio de todos os sistemas. Como já mencionamos, Deleuze coloca a arte ao lado da filosofia e da ciência como os três modos fundamentais do pensamento não da expressão do pensamento, mas do pensamento mesmo -, como as três dimensões do que ele chama "cérebro". A cada uma delas caberia uma relação própria, um devir próprio, um modo diverso de relacionar acontecimentos e estados-de-coisas, cabendo a arte a função de "concretizar" acontecimentos, tornar acontecimentos "blocos de sensação".

Contudo, embora tenha se ocupado de muitas artes, a literatura tem um lugar privilegiado no pensamento de Deleuze: já está presente em seus primeiros tratados não como objeto de análise enquanto tal, mas como instrumento. Basta atentar para a importância de L. Caroll em Lógica do sentido para se ter uma primeira noção do privilégio concedido à arte literária. Há muito tempo, os filósofos são escritores e este fato básico é suficiente para lançar luz sobre o interesse filosófico na literatura. É que ao pensar a literatura e as categorias literárias, o filósofo não procura analisar algo de inteiramente alheio ao seu próprio ofício, objeto exterior e distante, mas algo no qual está imerso. Se é verdade que a ficção (o romance, a poesia, o conto etc) é uma produção que envolve uma atividade muito distinta da atividade filosófica que produz os tratados, ensaios, romances-filosóficos, poemas-filosóficos, não é menos verdadeiro que, quando se trata da escrita enquanto tal, do estilo e dos problemas colocados pelas categorias de autor, obra, leitor, interpretação, entre outros, as dimensões da filosofia e da literatura interceptam-se. 


\section{Rosa e Deleuze: em torno de um campo problemático}

Ao falar da literatura, Deleuze buscará distinguir quais os elementos que definem o lugar de certa literatura que lhe interessa enquanto filósofo. Não falará da literatura de modo geral, nem estabelecerá conceitos universais com os quais se poderia tratar qualquer autor ou qualquer obra, mas destacará um tipo específico de literatura. Segundo Roberto Machado, "um dos interesses de Deleuze quando estuda a literatura é definir como se estrutura a linguagem de um tipo de literatura que, privilegiando uma referência a Nietzsche, pode ser chamada de extemporânea." (2009, p. 206).

Há, então, de se buscar os caracteres dessa literatura, sua marca de distinção, suas propriedades peculiares que a tornam um objeto de interesse para o pensamento filosófico. Ao fazer isso, nosso interesse concerne às possibilidades filosóficas abertas pelo escrito de Rosa sobre o qual nos debruçamos. Seria possível implicar Rosa - e mais propriamente seu Tutaméia - nessa categoria de literatura? Acreditamos que sim. Essa crença, suscitada pelas afirmações do autor em Aletria e hermenêutica precisa, então, ser comprovada pelo nexo entre o escrito de Rosa e os caracteres de uma escrita extemporânea descritos por Deleuze, uma vez que não há qualquer vinculação explícita entre o literato brasileiro e o filósofo francês.
Concebe-se, primeiramente, que o caráter distintivo da literatura extemporânea está ligado à criação, a qual implica trazer algo ao mundo, algo que previamente não existia. Por isso, há de se procurar na potência inovadora de uma obra o elemento de seu valor. Diz-se que a história somente se repete como farsa, omesmo pode-se dizer da literatura. Por maior que seja a admiração pelas obras do passado, pelos grandes clássicos ou gênios obscuros, a singularidade da escrita e do estilo exigem a perpétua reinvenção do fazer literário.

[...]Se o novo é o único critério, também o valor da linguagem literária - que tem como material as palavras e suas relações - diz respeito ao novo, ao inesperado, à mutação, à invenção. Se os materiais do escritor são as palavras e a sintaxe, o que conta são os aspectos sintáticos, a relação entre as palavras, o ritmo da língua mais do que os aspectos léxicos. Pois o importante não é a criação de neologismos - é a criação de uma nova sintaxe, são os efeitos de sintaxe, a sintaxe inesperada da qual um grande escritor é capaz. (MACHADO, 2009, p. 206).

Aparenta um truísmo dizer que o valor de uma escrita está em seu caráter inovador. É difícil conceber como poderia ser de outro modo e, ainda assim, não é difícil constatar a sedução que os modelos canônicos ou modismos passageiros podem exercer sobre uma parte dos literatos. De certo modo, toda obra literária para ser digna desse rótulo deve trazer algo de novo. Contudo, não se fala aqui de "novidade" ao modo de um valor geral e absoluto. A escrita extemporânea difere-se pelo fato de sua inovação atravessar o cerne da própria 
escrita: a sintaxe. Isso porque, uma escrita só pode ser dita inovadora se a potência do novo incide sobre o que é mais essencial, a própria escrita. Novos temas ou novas palavras, embora não inteiramente destituídas de valor, não implicam inovações literárias propriamente ditas. Se é certo que a literatura cumpre um papel dinâmico na evolução da língua, é correto afirmar que a força inovadora de uma escrita é uma justa medida do valor de uma obra literária.

Deleuze concebe esse papel dinamizador da literatura sobre a língua em termos de potencial de rebeldia da escrita com relação às formações sedentárias da língua padrão, "defende a existência de várias línguas numa mesma língua, com as quais o escritor poderá criar a sua ao desequilibrar a língua padrão dominante, desestabilizar as formações linguísticas canônicas." (MACHADO, 2009, p. 206-207). Ora, não é outra coisa que Rosa faz em Tutaméia: cada conto traz uma dinâmica sintática própria, adequada ao tema e ao efeito estético de tal modo que as inovações sintáticas não formam um quadro regular e recorrente, mas um feixe dinâmico, mutável, desviante.

Essa obra coloca-se no limite da língua portuguesa o qual não é limite com outra ou outras línguas, mas que é também limite da linguagem. Assim, a escrita de Tutaméia endereça-se para esse lugar em que a forma usual da expressão é abolida e, no limite, onde a própria expressão não parece encontrar lugar. Tal possibilidade aberta à literatura é concebida por Deleuze como um limite fora da linguagem:

Um limite da linguagem que tensiona toda a língua, uma linha de variação ou de modulação tensionada que conduz a língua a esse limite. E assim como a nova língua não é exterior à língua, tampouco o limite assintático é exterior à linguagem: ela é o fora da linguagem, não está fora dela (DELEUZE, 1997, 128).

O hermetismo de Tutaméia adquire, pois, o mesmo estatuto que na poética moderna e Rosa encontra no conto a via poética que abandonou depois de Magma. Assim, é possível compreender Tutaméia como um projeto eminentemente poético no sentido de acompanhar o desdobramento da poética do século $\mathrm{XX}$. O hermetismo das histórias passa então por ser de caráter tal que o efeito estético confunde-se com o efeito poético irredutível ao seu poder significante. Pode-se também falar de uma penetração da lírica moderna na prosa, que nesse livro atinge sua máxima expressão. "A tensão dissonante é um objetivo das artes modernas em geral", escreve Hugo Friedrich (1991, p. 15). Contudo, esse aspecto não parece ter penetrado as artes prosaicas de modo uniforme: o trato com a sintaxe não atinge em outros autores a experiência radical de Tutaméia; o caráter poético não se manifesta alhures com a mesma intensidade e vigor.

Em João Porém, o criador de perus, encontramos as seguintes construções: "Amar não é verbo, é luz lembrada" e "A vida é nunca e onde" Rosa (1979, p. 75). 
Mais do que metáforas, as construções categóricas expressam o que não se deixa expressar por uma construção equivalente. Tais construções destacam-se da ordem narrativa, recobrindo de sentido o enredo que normalmente as precede, e, no entanto, é o próprio enredo que deve apontar para sua significação.

Mantendo-nos ainda nesse conto, sobressaem as construções nas quais a palavra "porém" funciona de modo ambivalente como nome próprio e conector sintático, entre a significação da imagem gráfica e da imagem acústica. Contam-se quinze ocorrências desse tipo na história, incluindo o título: 1) "João Porém, o criador de perus"; 2) "Deixavam ao Porém o terreno"; 3 )"Porém tardava-os"; 4) “e Porém punha convicção no tossir"; 5) "Porém perseverava"; 6) “João Porém ouviu"; 7) "fechara com o Porém dos perus"; 8) "Porém prestou-lhes a metade surda de seus ouvidos"; 9) "Porém gaguejou bem"; 10) "Porém, sem se impedir com isso, fiel à forte estreiteza, não desandava"; 11) "Porém, Lindalice, ele a persentia"; 12) "Porém aqui suspendeu suma a cabeça"; 13) "E Porém morreu"; 14) "João Porém, ramarrameiro, dia-a-diário"; 15) "Porém! Porém...”.

No título não há ambiguidade, pois o aposto fixa o sentido de "Porém" como nome próprio. Contudo, há de se considerar primeiramente que o nome já traz em si mesmo um desvio de ordem sintática que transforma o ato convencional de nomeação numa sentença reduzida, enunciação da razão de fato que fez com que o personagem se chamasse João: "O pai teimava que ele não fosse João, nem não. A mãe, sim. Daí o engano e nome, no assento de batismo" (ROSA, 1979, p. 74). Ou seja, "apesar da" resistência do pai, o personagem acabou por se chamar João. Desde então, o sobrenome passa a ser signo desse "apesar de", que acompanha o personagem e conduz a sua história. $\mathrm{O}$ "caso" é um caso de "apesar de" e o aposto do título, como que resume a narrativa a ser contada: João, apesar de tudo permanecerá o criador de perus. Viver e criar perus são linhas disjuntivas que não se conciliam na história e, desse modo, o desdobramento da dessa incide sobre o título, quando se lhe aplica o método de interpretação circular sugerido pelo próprio Rosa. Nesse sentido, a ambiguidade do título, embora não evidente a uma primeira leitura, é estabelecido pelo desdobramento do conto.

Nesse caso, não se há de objetar também que as ocorrências nas quais o sobrenome vem acompanhado do pré-nome são isentas de ambiguidade. Como afirmamos, o nexo entre "Porém" e "João", implicam uma relação sintática, que tornam o nome uma sentença narrativa reduzida. Em "João Porém, ouviu, de susbrusco, firmes vezes" e "João Porém, ramarrameiro, dia-a-diário”, não ocorre nenhum elemento capaz de fixar a palavra "porém" como nome próprio. É verdade que ortograficamente não há e não pode haver ambiguidade: a grafia em maiúscula deixa claro o sentido nominal do termo, mas, é claro, as regras 
ortográficas nada afetam a imagem acústica que permanece remetendo a esse outro sentido, deslocando o nome de sua função neutra envolvendo-o na estrutura sintática.

O desvio estabelecido nas ocorrências 2 e 7 , contudo parecem de outra ordem. Aí a presença do artigo fixa definitivamente tanto gráfica quanto acusticamente o sentido substantivo do termo. Nem por isso, se haverá de dizer que essas construções estão livres de ambiguidade. É que efetivamente há um sentido substantivo do vocábulo, da conjunção substantivada que evoca um sentido impreciso, nebuloso ou aproximativo da função sintática. A princípio quaisquer conectores podem ser substantivados para remeter ao seu significado semântico aproximativo. Uma vez que "porém", como conjunção coordenativa adversativa, tem o sentido de objeção e contrariedade similar a "mas".

Aideia de contrariedade aqui é importante porque se coaduna com o enredo da história: João que, apesar da contrariedade do pai, acabou por se chamar João, herdou um terreno dos pais, um peru e duas peruas. Tendo sucesso na criação de perus, João passa a ser vítima da cobiça dos habitantes do lugar que, vendo o terreno como próprio à criação de perus, desejam comprar-lhe. Como artifício para que João vendesse o terreno diante de sua resistência, os habitantes resolvem por inventar que uma moça, Lindalice, em outro lugar o amava. É então que a narrativa de João passa a constituir um dilema entre a criação de perus e a vida que somente se realiza no amor.

Ora, quando os que inventaram a mentira decidem por desdizê-la, João não acredita, manifestando novamente a resistência e contrariedade própria de sua personalidade, caráter que por fim acaba por justificar o sobrenome. Ainda quando inventam de dizer-lhe que a moça morreu, João resiste a abandonar a "ideia fixa", sendo inútil também tentarem levá-lo a outra moça semelhante àquela inventada. A tudo João resiste e, apesar de tudo, morreu e "nem estudou a quem largar o terreno e a criação" (ROSA, 1979, p. 76).

Assim, o caráter inamovível de João, cujo tencionamento de largar a criação de perus somente foi possível pela força interna da sua "saudade sem saber de quê, causa para ternura inata" (ROSA, 1979, p. 75), justifica também um sentido implícito ao nome Porém como contrariedade e obstáculo. São esses dois sentidos distintos evocados por duas possibilidades diversas do termo: como conjunção substantivada de modo abstrato, "porém" há de indicar o próprio caráter de João e o sentido de suas atitudes em resposta aos assédios dos outros do lugar; como substantivo corrente, "porém" remete às atitudes dos outros para com João, cujo caráter resistente aos assédios o torna um verdadeiro obstáculo à pretensão daqueles.

$\mathrm{Na}$ maior parte das ocorrências $(3$, $4,5,8,9,10,12)$, contudo, é inegável a duplicidade de sentido criada pelo termo 
“porém”, sempre seguido por um verbo. Esse termo remete ora ao nome do personagem ora funciona como conjunção adversativa. Considere-se o inteiro parágrafo da ocorrência 3 e 4:

Já o invejavam os do lugar - o céu aberto ao público - aldeiazinha indiscreta, mal saída da paisagem. Ali qualquer certeza seria imprudência. Vexavam-no a vender o pequeno terreiro, próprio aos perus vingados gordos. Porém tardava-os, com a indecisão falsa do zarolho e o pigarro inconcusso da prudência. Tornaram; e Porém punha convicção no tossir, prático de economias quiméricas, tomadas as coisas em seu meio. (ROSA, 1979, p. 74) (grifo nosso)

Entretanto, pode-se objetar que o deslocamento do termo "porém" de nome próprio para conjunção implicaria desestruturação sintática das orações pela ausência do sujeito. É plausível a objeção. João é sujeito predominante nas orações do parágrafo antecedente, mas aqui é referido como objeto aparecendo sob a forma dos pronomes oblíquos "o" e "no". Gramaticalmente, "Porém" não poderia funcionar como conjunção sem instaurar uma grande confusão entre um sujeito oculto, instaurado por esse deslocamento, e o sujeito explicitamente estabelecido: "os do lugar". Nesse sentido, do ponto de vista das formações canônicas da língua, a ambiguidade parece não se sustentar, e o sentido das construções decide-se por fixar a palavra "Porém" como nome próprio e sujeito das orações nas quais figura.

O mesmo argumento pode ser usado quanto à ocorrência 5 no parágrafo subsequente ao que acabamos de analisar, no qual também se faz clara a referência aos personagens indeterminados, os habitantes do lugar, nas orações que antecedem aquela na qual o termo aparece: "Desistiram então de insistir, ou de esperar que, mais-menos dia, surgida alguma peste, ele desse para trás. [...] Porém perseverava, considerando o tempo e a arte, tão clara e constantemente o sol não cai do céu." (ROSA, 1979, p. 74). Idêntica também é a estrutura dos parágrafos das ocorrências 8, 9 e 2, sustentando-se aí o mesmo argumento gramatical contra a duplicidade de sentido.

Antes de se mostrar o limite dessa objeção, chama-se a atenção para o fato de que a ocorrência 10 não lhe sustenta. Aí, o parágrafo não envolve a oposição entre João e outros personagens:

Porém, sem se impedir com isso, fiel à forte estreiteza, não desandava. Infelicidade é questão de prefixo. Manejava a tristeza animal, provisória e perturbável. Se falava, era com seus perus, e que viver é um rasgar-se e remendar-se. Era só um homem debaixo de um coqueiro. (ROSA, 1979, p. 76)

Assim como o sujeito "os do lugar" figura em diversos parágrafos, sendo explicitamente expresso somente no primeiro e nos demais recolocado como sujeito oculto, aqui também o sujeito pode ser facilmente remetido à João, tornando desnecessária a menção inicial ao seu sobrenome. Aqui se pode objetar uma contradição interna: se afirmamos que na primeira oração desse parágrafo a palavra "porém" pode funcionar como conjunção ao invés de nome próprio, implicitamente deveremos assumir que 
as ocorrências anteriores devem ser fixadas, contrariamente, como referências ao sobrenome de João, recurso necessário para que se estabeleça o sujeito oculto dessa oração. Ora, mas o que afirmamos não é que todas as ocorrências da palavra "porém" devam ser interpretadas como conjunções, mas que o termo possui valor ambivalente, ora semântico ora sintático. Nesse caso, pode-se falar de uma permutação contínua e instável entre essa duas dimensões, uma variação dinâmica do sentido que, pendendo ora para este, ora para aquele caso, não deixa fixar o termo de forma unívoca.

Quanto às ocorrências anteriores nas quais a própria sintaxe, segundo os cânones gramaticais, parece decidir pelo sentido unívoco do termo, é preciso lembrar que o conto em Guimarães Rosa remete sempre ao sentido originário do "caso contado", ao princípio da oralidade explicitado quer direta quer indiretamente por meio da representação narrativa. É recorrente em Tutaméia que as histórias iniciem-se ou terminem por uma referência ao ato de contá-las. Em Arroio-das-antas termina-se por dizer: "Assim são lembrados em par os dois entreamor - Drizilda e o Moço, paixão para toda a vida." (ROSA, 1979, p. 20); mais explícito é ainda Rosa em Desenredo: "Do narrador aos seus ouvintes: [...]", (ROSA, 1979, p. 38), inicia e termina por dizer: "E pôs-se a fábula em ata" (ROSA, 1979, p. 40); Estória $n^{\circ} 3$ começar por uma análoga remissão à pré-exitência oral do caso: "Conta-se, comprova-se e confere que, na hora, Joãoquerque [...] (Rosa, 1979, p. 49), finalizando por: "Conte-se que uma vez." (ROSA, 1979, p. 52); em Gedeão, lê-se ao final: "Agora acabou-se o caso” (ROSA, 1979, p. 80); Reminição inicia-se pela seguinte autorreferência: "Vai-se falar da vida de um homem" (ROSA, 1979, p. 81); Lá, nas campinas traz em seus primeiros parágrafos um explícito relato de que o caso está supostamente sendo transcrito de um relato oral:

Está-se ouvindo. Escura a voz, imesclada, amolecida; modula-se, porém, vibrando com insólitos harmônicos, no ele falar naquilo. Todo o mundo tem a incerteza do que afirma. Drijimiro, não; o pouco que pude entender-lhe, dos retalhos do verbo. Nada diria, hermético feito um coco, se o fundo da vida não o surpreendesse, a só saudade atacando-o, não perdido o siso. Teve recurso a mim. Contou, que me emocionou. [...] (ROSA, 1979, p. 84).

Outras referências ainda se contam como a comprovar a remissão de Tutaméia a dinâmica originária do conto oral: o narrador de Mechéu termina por dizer: "Não falemos mais dele" (ROSA, 1979, p. 91); em Melim-Meloso diz o narrado: "Conto-me, muito, quando não seja, a simpática história de Melim-Meloso" (ROSA, 1979, p. 92). De outro modo, claro está que o conto Os três homens e o boi dos três homens que inventaram um boi é clara figuração da dinâmica mítica dos casos orais.

Estando João Porém, o criador de perus entre as histórias que remetem ao princípio de oralidade originário do conto por força da sentença inicial, "Ago- 
ra o caso não cabendo em nossa cabeça" (ROSA, 1979, p. 74), é forçoso considerar que a ambivalência do termo "porém" sustenta-se na duplicidade escrita/oralidade. Nesse sentido, a objeção de que a estrutura sintática dos parágrafos que contêm a maior parte das ocorrências do termo decide inequivocamente $o$ sentido do mesmo, embora se sustente, não contradiz nossa hipótese de que do ponto de vista da imagem acústica o termo permanece ambivalente. Argumentamos adicionalmente que o fato do sujeito das construções iniciais dos parágrafos estar indelevelmente destacado pela forma plural implica que a significação potencial do termo "porém" como conjunção e, portanto, da presença do nome do personagem como sujeito oculto não implica qualquer dificuldade hermenêutica.

É a ocorrência 11, porém, que melhor comprova nossa hipótese:

Vem que viam que ele não a esquecia, viúvo como o vento. Andava o rumo e suas aumentadas substituições. Ela não estava para trás de suas costas. Porém, Lindalice, ele a pressentia. Tratava centena de peruzinhos em gaiolas, e outros tantos soltos, já com os pescoços vermelhos. (ROSA, 1979, p. 76).

Trata-se da única ocorrência na qual o termo "porém" quer gráfica quer acusticamente parece pender mais para a função conjuntiva. Em nenhum momento do conto Rosa o utiliza com essa função de forma inequívoca e, mesmo aqui, a possibilidade de o sujeito estar a ser repetido (algo que não vai de encontro aos padrões formais da língua), força-nos a considerá-lo tão ambivalente como nas demais ocorrências. É justamente a série de ocorrências, que distribui a cada um delas esse efeito ambivalente, valendo pois o predicado da série por princípio de desestabilização das construções individuais.

Por fim, a última ocorrência do termo que finaliza o conto é corolário da ambivalência estabelecida pela série inteira: "Ele fora ali a mente mestra. Mas, com ele não aprendiam, nada. Ainda repetiam só: —“"Porém! Porém...' Os perus também.” (ROSA, 1979, p. 76). Aqui a ambivalência chega ao seu limite e o termo repetido tanto pode ser compreendido como dupla referência ao personagem, como dupla conjunção a indicar consternação, assim como de modo a que a primeira se referia ao nome e a segunda funcione como conjunção, aproveitando-se do efeito indeterminativo das reticências.

A função desestabilizadora do termo "porém” em João Porém, o criador de perus justifica, portanto, colocar o autor de Tutaméia entre os escritores referidos por Deleuze como extemporâneo. Reconhecemos no seu uso da sintaxe os atributos inovadores que permitem dizer que, ao levar a língua aos limites de suas formações canônicas e mesmo ultrapassá-las, Rosa produz um "devir-outro" da língua. Conforme observa Roberto Machado, considerar o estilo sobre esse ponto de vista implica dizer que o estilo é: 
Quanto ao conceito de estilo, Roberto Machado o esclarece: "O estilo - para Deleuze, uma variação de variáveis, uma variação contínua que diz respeito principalmente à sintaxe - é o que permite que o escritor crie uma língua estrangeira em sua própria língua, escreva em sua própria língua como se ela fosse uma espécie de língua estrangeira" (MACHADO, 2009, 207).

Uma nova sintaxe que possibilita que o escritor produza um devir-outro da língua, um "delírio" que a faz sair dos eixos, dos trilhos, que a faz escapar do sistema dominante. Assim, ele privilegia na literatura o modo como o escritor decompõe, desarticula, desorganiza sua língua materna para inventar uma nova língua marcada por um processo de desterritorialização. Como? Não pela mistura de língua diferentes, mas por meio de uma construção sintática, da criação de novas potências sintáticas, gramaticais - seria ainda melhor dizer assintáticas, agramaticais - que lhe dê um uso intensivo, oposto ao uso significativo ou significante. (MACHADO, 2009, 207).

Fala-se de um "delírio" como um desvio no corpo da própria língua. E é nesse sentido que o projeto de Tutaméia converge para esse conjunto de escritos extemporâneo, experiências radicais da sintaxe: aqueles que apelam para a agramaticidade e aqueles cujas construções são equivalentes a fórmulas agramaticais.

A fórmula de Deleuze para a literatura é, portanto: "levar a linguagem ao limite". Ao mesmo tempo, à literatura parecem dirigir-se exigências outras (políticas, sociais) que incessantemente a interrogam quanto ao seu conteúdo, ao que pretende dizer e pensar. Não se deve falar aqui de uma relação entre literatura e pensamento. A rigor, a literatura é pensamento, um modo de pensar próprio e independente. Daí que no último século a filosofia tenha se voltado para a literatura, interrogado-a em seu ser próprio: aos romances e poemas filosóficos sucederam interesses filosóficos pela literatura, por exemplo, as práticas discursivas de Foucault que se implicam a enunciados da literatura, da filosofia e da ciência até a litero-filosófica de Deleuze. De fato, muito confunde a arte com o mero entretenimento aquele que busca além da experiência estética, algum outro "pensamento". A literatura diz algo por meio de si mesma enquanto construção estética, de modo a que se pode resumir essa constatação na máxima de Nietzsche: "melhorar o estilo significa melhorar o pensamento". (NIETZSCHE, 2008, p. 226).

Quando estamos diante de um autor como Rosa, o que se pergunta é exatamente o quanto suas construções sintáticas não usuais inserem-se no corpus da língua, o quanto podem contribuir para a evolução da língua. De certo modo, podemos falar de tais construções, a seguir o pensamento de Deleuze, como monumentos estéticos, sob a condição de que ressalvemos o fato de que a força criativa que os atravessa não se esgota em si mesmos; ao contrário, é próprio dos grandes projetos literários endereçarem desafios à própria língua, revelar seus limites e, assim, traduzirem-se na força motriz de seu desenvolvimento. Portanto, a experiência estética, particularmente, a experiência estética em 
Rosa há de se constituir como exercício de pensamento enquanto tal, não sendo sem razão que já no primeiro prefácio o autor sentencia: "Não é o chiste rasa coisa ordinária; tanto seja porque escancha os planos da lógica, propondo-nos realidade superior e dimensões para mágicos novos sistemas de pensamento" (ROSA, 1979, p. 3), isso é, a reconstrução da experiência por meio de um desvio do ordinário e do bom senso. Esse sentido da obra de arte em confronto com o quotidiano e com o bom senso parece-nos bem explicitado, quer nos prefácios, quer nas histórias de Tutaméia.

Que significa, pois, esse movimento pelo qual a arte é capaz de desconstruirreconstruir o sentido de modo a estabelecer o que se pode chamar de uma experiência do extraordinário? Encontraremos na própria materialidade da escrita o que esta nos propõe como extraordinário ou, pelo contrário, é no que lhe falta, no que está ausente nos interstícios vazios da obra e na obra que nunca se acaba completamente que devemos procurar esse novo sentido.

No prefácio intitulado de "Aletria e hermenêutica”, (ROSA, 2001, p. 29), o autor nos apresenta dois pontos importantes sobre a concepção de arte literária: primeiro, que a literatura implica um tipo de pensamento; segundo, que por meio de um tipo de literatura, arquetipicamente representada pela figura da anedota, a transcendência se estabelece como passagem que vai do ordinário ao extraordinário, do cotidiano ao sublime, sem cair numa perspectiva mística, por vezes, usual nas leituras dos textos de Guimarães Rosa. A ideia aqui é pensar o texto rosiano do qual tratamos, Tutaméia, como uma maneira de escapar ao supra-sensível em função do mais profundo empirismo ou daquilo que Deleuze chamava de "ser do sensível" "bloco de sensações, "composto de perceptos e afectos" (DELEUZE, 1992, p. 213-255). Para o filósofo francês, o artista coloca-se nessa posição, de criador e inventor de um ser de sensação a partir da qual cria em função do extraordinário.

Qual é o ser do sensível? De acordo com as condições desta questão, a resposta deve designar a existência paradoxal de 'alguma coisa' que não pode ser sentida (do ponto de vista do exercício empírico). [...] É a intensidade, é a diferença na intensidade que constitui o limite próprio da sensibilidade. Tem ela, portanto, o caráter paradoxal deste limite: ela é o insensível, o que não pode ser sentido, porque está sempre recoberta por uma qualidade que a aliena ou que a contraria, distribuída num extenso que a subverte e a anula. Mas, de outra maneira, ela é o que só pode ser sentido, aquilo que define o exercício transcendente da sensibilidade, na medida em que ela faz sentir e, por isso, desperta a memória e a força do pensamento. (DELEUZE, 2006, p. 331-332).

Conforme assinala Roberto Machado:

Escrever é uma tentativa de libertar a vida daquilo que a aprisiona, é procurar uma saída, encontrar novas possibilidades, novas potências da vida. Pois, em continuidade com sua concepção do exercício do pensamento, ou do que significa pensar, a criação artística é, para ele, o ato de tornar visível o invisível, tornar audível o inaudível, tornar dizível o indizível - ou, para formular essa ideia em toda a sua abrangência, tornar pensável o impensável. (MACHADO, 2009, p. 221). 
A arte compreendida aqui não como uma transição para o pensamento, uma ponte, um meio, mas sim como o pensamento mesmo, que se expressa sob a forma de estados perceptivos, "fazendo estourar percepções vividas" (DELEUZE, 1992, p. 222), uma espécie de infinito da própria sensibilidade. Ao pensar a obra de arte como bloco de sensações, Deleuze procurará escapar da transcendência que se alimenta do além-mundo (místico, teológico) e problematizará a escrita, a literatura enquanto imanência, território do puramente sensível.

A arte desfruta então de uma aparência de transcendência, que se exprime não numa coisa por representar, mas no caráter paradigmático da projeção e no caráter "simbólico" da perspectiva. A Figura é como a fabulação segundo Bergson: tem uma origem religiosa. Mas, quando ela se torna estética, sua transcendência sensitiva entra numa oposição surda ou aberta com a transcendência suprassensível das religiões. (DELEUZE, 1992, p. 248-249).

Embora Deleuze, na citação acima fale da arte figurativa, o mesmo pode ser aplicado à arte literária. Isso porque, o que é mais próprio à arte, sua esteticidade é o que implica nessa outra ideia de transcendência, que na verdade, não se trata de transcendência, mas de imanência, pura e absoluta. Nessa direção, o metafísico e o místico são, portanto, dispensáveis para a compreensão daquilo que poderíamos chamar de sublime. É à própria dimensão da linguagem e da escritura que devemos nos dirigir e aos seus movimentos e devires.
A pergunta que se impõe diante da crítica deleuzeana é a seguinte: que significa pensar o mundo ou como dizer o mundo? Será que o papel do escritor é povoar a nossa consciência de objetos. Dar a essa mesma consciência um estatuto de legítima organizadora. Separá-la do mundo, humanizá-la, constituir uma estrutura, um plano de organização lógico, regular, métrico?

Em "Tutaméia", não há mais uma escrita que se constitua em função da transcendência conforme a tradição metafísica sempre indicou ao termo e nem um pensamento em função da representação, como se a escrita não passasse de mero reconhecimento de estados vividos. O texto de Rosa pode ser pensado enquanto um livro que se abre e não apresenta a partir de um fácil e vulgar empirismo as potencialidades da escrita que escapa à percepção pura imediata. Esse vazio em Tutaméia, princípio de composição da obra, conduz necessariamente para um movimento de ultrapassagem da materialidade do livro em favor de uma imaterialidade da obra sempre por vir, sempre por nos desafiar e provocar.

[...] qual será este agente, esta força que assegura a comunicação? O raio que fulgura entre intensidades diferentes, mas é precedido por um precursor sombrio, invisível, insensível, que lhe determina, de antemão, 0 caminho invertido, como no vazio. (DELEUZE, 2006, p. 174-175).

Não falamos das intenções ocultas do autor ou reconstrução cognitiva do leitor, mas de uma implicação nas sensações, 
nos perceptos e afetos na própria dimensão sensitiva da obra.

Não obstante, pode-se dizer que Tutaméia encerra a oobra de Rosa, mas a encerra justamente apontando para esse inacabamento essencial. Assim, o Quod erat demonstrandum

de "Aletria e hermenêutica" - "O livro pode valer pelo muito que nele não deveu caber", (ROSA, 2001, p. 40), ou seja, por seu expresso que não se limita ao designado e nem ao significado imediato da escrita e nem de uma imediata recepção do leitor, mas que constitui sentido àquele que afeta e transforma, um inacabamento essencial que atravessa e perturba 0 livro; um livro-fluxo, aberto, constante e que modifica o espírito daquele que o contempla. Assim sendo, não fiquemos presos à ideia do vazio. É preciso agora suplantar essa tese em função de que esse inacabamento é uma estratégia da criação (do autor) para compreendermos que, no sentido dessa ausência, há uma ausência como sentido mesmo. Ausência que na verdade, é presença, dado, como dissemos mais acima, que se trata de um insensível ou ser do sensível, um disfarce oculto, sorrateiro, menos visível, “[...] Portanto, ele só vale na medida em que pretende não dizer alguma coisa, mas dizer o sentido do que ele diz". (DELEUZE, 2006, p. 179). O vazio então é um dos elementos mais importantes em Tutaméia; vazio e ausência, entendidos por nós enquanto expertise do jogo da escrita, da criação literária do autor como fabulador do livro. O mais importante no texto de "Tutaméia" é aquilo que torce a linguagem, "à condição de levar em conta o perpétuo deslocamento invisível e silencioso do sentido linguístico" (DELEUZE, 1992, p. 179), dando sentido ao livro, ultrapassando-o, não como um escrito possível que prolongaria a experiência da escrita (como se diz de todo grande autor, de tudo que poderia ter escrito ainda não fosse a fatalidade da morte). Não está em jogo a continuidade ou prolongamento da obra pelo leitor; não é o vazio do prolongamento do que não será escrito. Estamos falando da qualidade de percepção do leitor, da condição em ser afetado pelo ser do sensível que a obra produz, pelas modificações que pode suscitar em quem a lê, pelos dinamismos que pode desencadear no leitor, pelos infinitos mundos que pode criar, pela violência que provoca no leitor e pelos encontros que proporciona, apresentando-nos a literatura como um campo problemático, onde "apreender a intensidade, independentemente do extenso, ou antes, da qualidade nos quais ela se desenvolve, é o objeto de uma distorção dos sentidos". (DELEUZE, 2006, p. 333).

Diz-se de Tutaméia que encerra a obra de Guimarães Rosa; espera-se que, em sua terminalidade, lance luz sobre a escrita passada e sobre o próprio autor, lugar da escrita possível, futura e não realizada. De certo modo, essa expectativa é contrária à opinião que divide a obra entre o escrito maior e os escritos menores, mas nem por isso diz o exato contrário. Se Tutaméia vale por um testemunho da obra não é pela razão de ser 
o grande escrito, realização final e perfeita de uma escrita que enfim encontra a si mesma, mas, justamente, por deixar compreender a distância que inicialmente é intransponível entre a infinitude da escrita e o inacabamento essencial da obra, mas que não o é, pois seu sentido é expresso ardilosamente a partir daquilo que afeta o leitor, esse mesmo, que, estabelece uma cumplicidade profunda com o texto literário e seus perceptos e afetos. Falamos do autor (nesse caso, Guimarães Rosa) como potência criativa e a obra como um monumento que existe em si, não se reduzindo mais à figura do autor, "[...] a coisa tornou-se, desde o início, independente do seu "modelo" Deleuze (1992, p. 213)”. Ora, se Guimarães Rosa, ao subtitular Tutaméia, "Terceiras estórias", efetivamente põe fim à expectativa da proliferação indefinida da escrita, por outro lado, ele não impede a proliferação de novos sentidos, "por meio de novas maquinações" (DELEUZE, 2000, p. 75), assim, o expresso das proposições que perpassam o livro se não faz preparativo para uma nova escrita, transvasa e muda o espírito de quem a contempla.

\section{Conclusão}

A proposta do texto foi apresentar os problemas impostos a partir de uma leitura da obra Tutaméia, de Guimarães Rosa, buscando apoio na filosofia de Deleuze, não como uma forma ou maneira de hierarquizar a relação filosofia e li- teratura, mas sim, constituir um campo possível de conversação e implicação. Sabendo-se que Deleuze fala-nos da literatura enquanto campo de perceptos, por meio de uma experimentação com a linguagem, com a língua, consideramos o livro Tutaméia do ponto de vista da experiência estética. Isso significa que vislumbramos na escrita o processo e o produto da atividade artística enquanto efeito de uma experiência do pensamento.

Nessa direção, compreender Tutaméia como um exercício de pensamento que escapa às categorias lógicas ordinárias da língua e da sua tradição de designação e significação. Tutaméia, então, como sendo um movimento no interior da própria escrita e consequentemente da própria língua, ou seja, a proposta de Rosa era a de tentativa de construir seu projeto literário a partir dos limites da língua. Essa experimentação leva-nos a pensar o livro como obra de arte, composto de afetos e perceptos; na acepção de Deleuze, condição segundo a qual o pensamento abre-se para suas infinitas possibilidades. Para Vera Novis (1989, p. 138), "Tutaméia, tomada em conjunto, propõe a provisoriedade de todo fim, a infinitude do narrar". E seguindo-se tal perspectiva, dizemos que é uma obra inesgotável, em especial, por aquilo que ela provoca, pelos seus efeitos no leitor.

Guimarães Rosa consegue, em sua genialidade característica, inventar e criar mais que uma estrutura estática, carregada de normas, segmentos e bom 
senso. Contrariamente, o livro Tutaméia mostra uma dinâmica imanente que 0 movimento circular da releitura deve revelar. Uma sorte de explosão do extraordinário no quotidiano, irrompendo em sobressalto o vazio em direção ao que escapa à imediata compreensão.

Tutaméia, na singularidade que lhe é própria, constitui-se num livro que se faz a partir da ausência do livro; de uma obra que estabelece um movimento infinito em direção à obra sempre inacaba$\mathrm{da}$, afastando-se assim da possibilidade imediata de uma identidade entre pensamento e representação, retirando-nos do terreno da opinião e fazendo apreender que a literatura é a "arte de restituir o infinito”. (DELEUZE, 1992, p. 253).

Les illusions de la langue: considérations concernant le travail Tutaméia, Guimarães Rosa - Une rencontre avec Gilles Deleuze

\section{Abstract}

The purpose of this study is to approach the Guimarães Rosa's Tutaméia book from as a work of art. For this, we ask: What makes a book a work of art? In this journey, we use an approach that has the thought of Gilles Deleuze its main reference. If literature is interested in philosophy, if Rosa himself in the preface "Aletria e hermanêutica" goes beyond the limits of artistic production in the direction of bringing a concept of literary, philosophy is also interested in literature, either does it expect to engage in a certain system of thought, either because on it, the philosophy finds it a refuge for all systems. As already mentioned, Deleuze puts art by the side of philosophy and science as the three fundamental modes of thought - not the expression of thought, but the very thought itself - as the three dimensions of what he calls "brain." To each one of them, a proper relation would fit, becoming one of their own, a different way to relate events and states-of-things, while the role of art the "embed" events, making events "blocks of sensation." The considerations, therefore, that suggests that an understanding of the book by Rosa, in which sometimes uses the intertextual elements, it is still an eminently intratextual understanding, a perspective of the book by the book that refuses to search in the personaauthor's figure or in categories borrowed from psychology, psychoanalysis, sociology or any other science, the needed elements for it's support. We'll seek, thereby, to establish an understanding of the book and at the same time, to leave opened the multiple perspectives on the work, once is proper to this perspectivist comprehention to leave the book opened, as the narrative infinity.

Key-words: Literature. Work of art. Philosophy. Block sensation.

\section{Referências}

ROSA, João Guimarães. Magma. Rio de Janeiro: Nova Fronteira, 1997.

Tutaméia: terceiras estórias. 5. ed. Rio de Janeiro: J. Olympio, 1979.

BLANCHOT, Maurice. O livro por vir. São Paulo: Martins Fontes, 2005. 
DELEUZE, Gilles e Felix Guattari. Mil platôs. São Paulo: Editora 34, 1995, v. 2.

DELEUZE, Gilles. Crítica e clínica. São Paulo: Editora 34, 1997.

DELEUZE, Gilles. Lógica do sentido. São Paulo: Perspectiva, 2000.

Deleuze, Gilles. Diferença e repetição. Rio de Janeiro: Graal, 2006

DELEUZE, Gilles et GUATTARI, Félix. Percepto, afecto e Conceito. In. O que é a filosofia? Trad. Bento Prado Jr. e Alberto Alonso Muñoz. Rio de Janeiro: 34, 1992, p. 211-255.

FRIEDRICH, Hugo. Estrutura da lírica moderna. São Paulo: Livraria Duas Cidades, 1991.

LARROUSSE CULTURAL. Dicionário $d a$ língua portuguesa. São Paulo: Nova Cultural, 1992.

MACHADO, Roberto. Deleuze a arte e a filosofia. Rio de Janeiro: Jorge Zahar, 2009.

NIETZSCHE, Friedrich. Humano demasiado humano II. Tradução de Paulo César de Sousa. São Paulo: Companhia das Letras, 2008.

NOVIS, V. Tutaméia: engenho e arte. São Paulo: Perspectiva, 1989. 